\title{
Factors blocking the development of north - central Rzeszów
}

\author{
Adam Rybka, Rafał Mazur \\ Rzeszów University of Technology \\ Faculty of Civil and Environmental Engineering and Architecture \\ e-mail: akbyr@prz.edu.pl,rmazur@prz.edu.pl
}

\begin{abstract}
Rzeszów is one of the best developing cities in Poland. Once the small HQ of a principality - due to complicated historical conditioning - it has now become a place where an increasing number of people choose to live. The city with its bursting life, streets and squares starts and ends, however, in an area which only a few dozen years ago still catered for one fifth of the current population. The main reason for this phenomenon is the presence of spatial barriers, which significantly limit the development of the central urban area. This article analyzes the elements, which block the development of the north-central part of Rzeszów. An appropriate diagnosis of the problem may in the future allow the right actions in urban planning to be taken in order to cross these barriers. This may lead to the future development of areas with huge urbanization potential. Investments undertaken by city authorities to develop the northern peripheries of Rzeszów may trigger the development of the central district in this direction. This may occur as a result of concrete design interventions. The new part of the central district should have the scale and proportions of urban space that answer to the needs of a dynamically developing capital of the Podkarpacie region.
\end{abstract}

Key words: urban reshaping, central Rzeszów, scale and proportions of urban space, revitalization of degraded areas

\section{Introduction}

\subsection{Analysis problem}

Since the 1990s central Rzeszów, especially the old town, has become the hub for many investments, which saw the revitalization of the old and construction of new objects. This has significantly increased the quality of this space. Investments did not, however, include the north-central part of the city. It is worth mentioning here the area north of Marszałek Piłsudski avenue from the Dmowski roundabout to where the river Wisłok bends. This area has enormous city-forming potential. It's as if it was forgotten by residents - the area is incomparably neglected compared to areas south of Marszałek Piłsudski avenue. There are 
many reasons for this - barriers that have made the development of this part of the city impossible. The first is the avenue itself, which did not take on the form of a representative street. Its function was relegated to serve vehicular traffic. Another barrier are railway areas, which are lacking in crossings, something that effectively blocked the development of the central district to the north. An important element with untapped potential is the area near the Dmowski roundabout.

Figure 1: Buildings in Rzeszów in 1935 (author: Paweł Kozioł)

\subsection{The condition of analysis}

The urban transformation of Rzeszów is the theme of many scientific works. Honorable mention should be given to the four-part interdisciplinary collective work entitled "Dzieje Rzeszowa"[1], [ed. "Rzeszów through the ages"], which contains all the previous scientific work about the spatial development of the city. An article entitled "Powiększyć miasto" [2] [ed. "Enlarging the city"] by Stanisław Krzaklewski continues on this path and presents many conclusions concerning design solutions.

Issues concerning the transformation of the modern central district are present in all the works covering the city's urbanization. It is especially worth mentioning works that have appeared 
since the 1960s, which criticize modernist assumptions for shaping cities based on the domination the automobile. A critique and concrete propositions offered by Jan Gehl [3] and Jane Jacobs [4] have shed light on many reasons for the slow death of important fragments of cities.

\subsection{Methods of analysis}

Problems concerning the blocking of the development of north-central Rzeszów may be tackled via an analysis of the existing state of play, historical conditioning, as well as solutions which have worked well in other parts of Rzeszów and in other cities. An observation of the way space functions is key in the diagnosis of the most important barriers for the development of the area under scrutiny. In the academic year of 2015/2016, and as part of the subject entitled "Przekształcenia urbanistyczne" [ed. "urban transformations"], taught at The Faculty of Civil and Environmental Engineering and Architecture at the Rzeszów University of Technology, analysis was carried out with a group of students, geared toward the creation of a design concept for the development of north-central Rzeszów. Photographic documentation and urban analysis became the point of departure for further study.

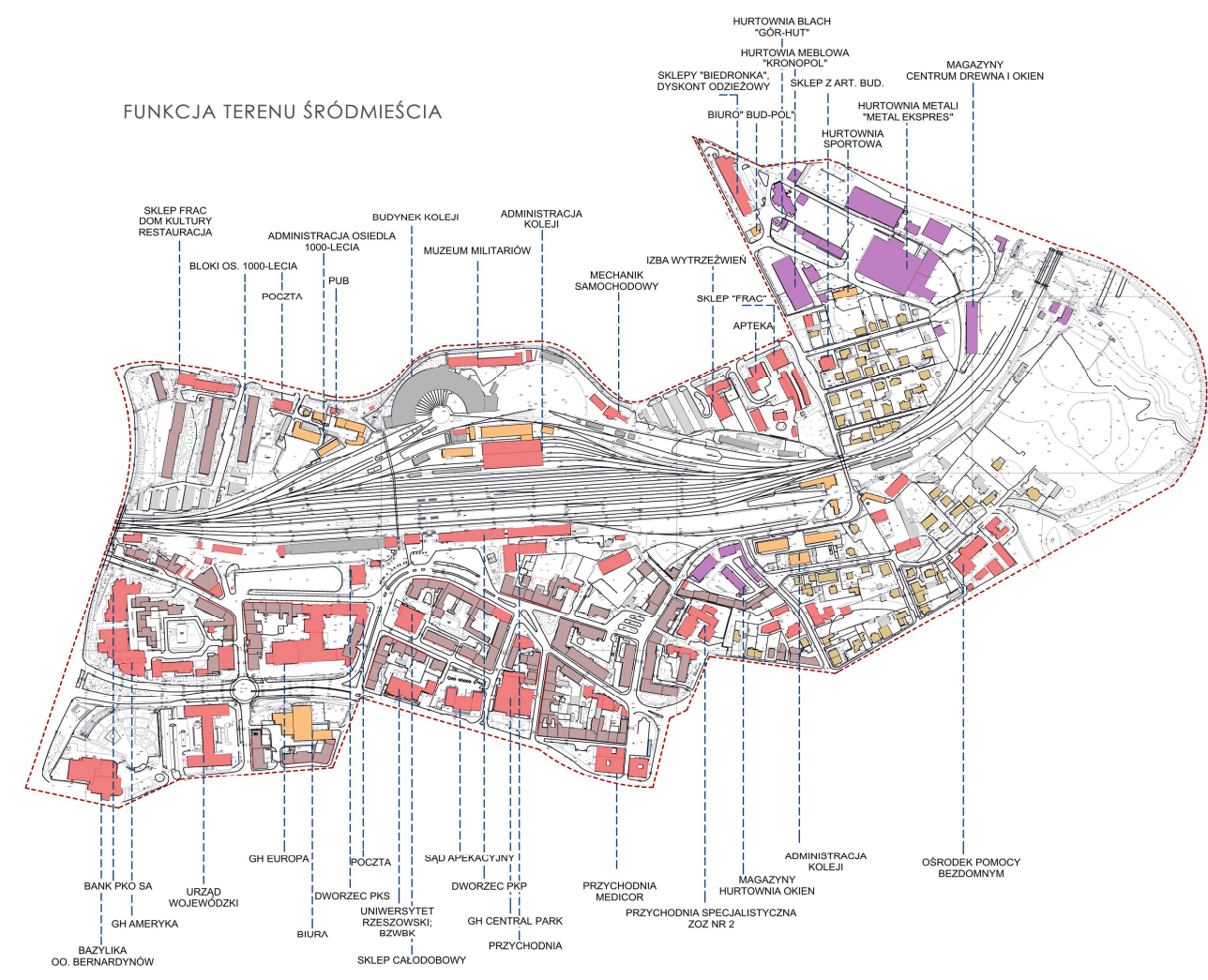

Figure 2: Analysis of function of the north-central Rzeszów (authors: Magdalena Grygiel,

Jolanta Wywrot) 


\section{Elements blocking development}

\subsection{Marszałek Piłsudski avenue}

Marszałek Piłsudski avenue is one of the most important communication networks in Rzeszów. Until a bypass was built it was the main transit artery from eastern to western Poland. Its trajectory encroaches upon the historical structure of the city including the New Town Square, which crystallizes the city plan. Together with the destruction of the historical structure of that part of the city, the construction of the avenue cut the central district in two. The northern part became the less attractive of the two in terms of investment. The structure of the avenue indicates domination of vehicular traffic. Pavements are limited to a bare minimum and in some places they do not fulfill regulations in terms of width. Despite the fact that the avenue has not been a transit road for some few dozen years, in some sections it is reminiscent of a duel carriageway and constitutes a clear barrier for pedestrians.

The location of the avenue allows the creation of a representative road, which would be accessible to pedestrians, as well as being a magnet for all kinds of retail services. The buildings located along the avenue are often too chaotic and even face the other way. Additional development creating a proper frontage would allow the space to be ordered and thus gain a central urban character. The avenue cross-section itself, should be redesigned as to limit traffic and create a space for pedestrians, cyclists and high reaching greenery.

\subsection{Railway areas}

One of the largest barriers to the development of central Rzeszów to the north are the railway areas. At one time they were located off the beaten track, but currently they cut the city in half right down the middle. The areas on either side of the tracks constitute completely different space. The southern part is brimming with life, whereas the north is a mix of residential areas with industrial and warehousing land. One gets the feeling that the latter part is reminiscent of city outskirts rather than being its central fragment. Due to its location within Rzeszów, this area should be full of urban city buildings. The railway tracks constitute the most significant border in the north-central part of Rzeszów. Crossing these tracks via an increased number of tunnels and attractive footbridges for pedestrians and cyclists is the largest challenge faced by spatial planners in the coming years.

The area in and around the railway station is also an important element. The city does not only serve its inhabitants but also visitors, whose first taste of Rzeszów is often at the train station. It serves as a gate whose quality dictates first impressions of the city. In order to liven up the north-central district one must not neglect public space around the train and bus stations. The bus station needs to be renovated. The area in which it is located could be builtup in order for Grottger street (between Grunwaldzka street and Asnyka street) to gain a second frontage. Bus terminals and platforms for long distance journeys could be placed underground. Platforms for suburban busses could be located along the historical warehouses adjacent to the station, which may be utilized for retail purposes, especially as restaurants and cafes. There is an undeveloped square in front of the railway station, which currently serves 
as a car park. The car park could also be moved underground. The area in front of the station should be representational.

Buildings around the railway tracks were in the past used for technical purposes. These historical buildings are a wonder in form and detail. Many of them can be used for different functions. The former steam engine building - thanks to its form- could house a modern art center. A concert hall could be built where the half-circular dome part once stood. The whole area has an interesting fore-ground, which could constitute high quality public space.

The introduction of new buildings to part of the railway area introduces a better acoustic and aesthetic standard to the space along the rail tracks. Office and retail buildings with acoustic facades separate the railway from the city in a natural manner. They create a frontage by creating a new space in the very center of the city. Such a process has already been successful in many other cities.

\subsection{The bend in the river Wisłok}

Mastering the barriers connected with the functioning of the railway creates possibilities of using very attractive terrain located in the bend of the river. This area, which is based in the center of Rzeszów, is currently practically undeveloped. It contains a few houses, a warehouse and elements of the heating infrastructure. The multi-functional development of this area together with streets and squares that open towards the river seems to be a necessity due to the attractive nature of this area.

An important border, which prevents the development of the central district to the north, is the river itself. A lack of crossings such as bridges means that the potentially attractive location of this area is cut off from the rest of the city. The building of a new bridge connecting the central district with Generał Kazimierz Dworak street, which is an extension to Rejtan street, would mean that the areas that are today inaccessible would become attractive for investment.

A new north-central district located at the river Wisłok bend could offer residents well balanced development, in which pedestrians and cyclists can feel comfortable. Vehicular traffic is introduced in a capacity allowing good communication, but not hampering urban life, which takes place on streets and squares. The urban layout should be based on a traditional formula of block development, which is deeply rooted in European culture. Life in this public space could be buzzing at ground level where retail outlets could be located. The attractiveness of a well communicated area that opens onto the river guarantees the profitability of creating new places for people to meet, such as bars, cafes and restaurants, so common in a modern city. Higher condignations should have a mixed purpose so that the apace is used around the clock. Some of the buildings located nearer to the train tracks may function as offices or public use buildings. Buildings nearer the river serve as an attractive location for apartments. 


\subsection{Dmowski roundabout}

The place that sees the most vehicular traffic in Rzeszów is the Dmowski roundabout. This area, despite being a natural junction for the whole city, is not friendly to pedestrians due to its large distances. A few dozen years ago two national arteries still crossed here: east-west with north-south. The barrier, which has inhibited the development of this special city, can be found in the difficult political conditions. During the PRL-era [ed. Polish People's Republic, between 1952-1990], this space - so important in terms of the city's composition - was used to manifest political ideology. A huge foreground was created to underline the rank of the building that housed the Board of the People's Council. The domination of the authorities was at that time underlined additionally by a monument to the "Czyn Rewolucyjny" [ed. "revolutionary act"]. Due to its scale and location it became an important element of the city. The land surrounding the roundabout is today reminiscent more of a suburban area with a shopping center rather than a well developing city. This huge hole at its very heart does not seem to be justified from an economic and especially a social point of view.

The problem of the monument has provoked local discussion for more than 40 years: a most important place in the city saw the construction of a giant monument, which went beyond the scale of Rzeszów's development. The form was designed by professor Marian Konieczny, who was at that time rector of the Academy of Fine Arts in Kraków. Its construction engulfed huge funds and became one of the most important elements reflecting the structure of the city. It is also a sore reminder of Poland's painful past. So should this remembrance dominate the city? Rzeszów residents have different answers to this question. Two opposite views dominate public opinion. One asserts that the monument should be left as a historical element and the other wants to demolish an object, which it sees as a symbol of captivity.

The area around the Dmowski roundabout is characterized by a scale, which does not answer to the psycho-physical conditioning of man. The distances that must be covered by a pedestrian to get from fragments of intensive development at the old town to the buildings located at the roundabout reach up to $300 \mathrm{~m}$ meters. The undeveloped area has become a barrier, which separates Rzeszów's old town from the northern part of the city thus blocking development in this direction. In most European cities central junctions are usually surrounded by intensive development. They become a main meeting point for residents and visitors and are an important element to the image of the city. A similar situation can be seen in Warsaw in the area surrounding the Palace of Culture.

\section{Conclusion}

Conquering the barriers mentioned in the article via complex urban planning would allow the fast development of the north-central district, as well as neighboring areas. The first thing that needs to be created is a communication plan that takes into account tunnels underneath the railway tracks and a bridge over the Wisłok river appropriate for the rest of Rzeszów. Vehicular communication should not be centered on duel carriageways but guarantee the largest possible network of roads with equal traffic. Pedestrians should be allotted a special role. Good quality public space will guarantee that the land is attractive. Due to its location it has a chance for effective development. 
A well-organized communication network, which brakes the current barriers will allow the development of new areas. The reclaimed land located in the center of the city will undoubtedly become a space of great quality for Rzeszów. The buildings that already exist and which are often of great historical and aesthetic value, will thus be appropriately managed. The development of the north-central area is also a great chance for Rzeszów, which currently lacks urbanization in its center on a scale appropriate to the stature of the city. The old town, which today plays the role of the center of town, is very attractive but its character is typical for a Galician regional city. The scale of the buildings that often do not rise above two condignations cannot cater for the needs of a developing city. The creation of a new part of the central district with five storey buildings will answer to the need for offices and retail space. The reclaiming of land that is currently dead would also speed up the development of the Tysiąclecie, Pobitno, Staromieście and Załęże residential areas.

The elements presented above, which block the development of the north-central district, will continue to impact Rzeszów with increasing intensity. Braking the existing barriers should become a priority for immediate urban planning.

\section{References}

[1] Dzieje Rzeszowa, tom I - IV, Libri Resovienses, Rzeszów 1994-2012.

[2] Krzaklewski S., Powiększyć miasto, „Czasopismo techniczne Politechniki Krakowskiej” 3-A 2008, p. 127-133.

[3] Gehl, J., Cities for people, Island Press, Washington 2010.

[4] Jacobs, J., The Death and Life of Great American Cities, Vintage Books Edition, New York 1992. 